\title{
Re-assembled casein micelles improve in vitro bioavailability of vitamin D in a Caco-2 cell model
}

Yifat Cohen ${ }^{\mathrm{a}}$, Moran Levi ${ }^{\mathrm{b}}$, Uri Lesmes ${ }^{\mathrm{a}, \mathrm{b}}$, Marielle Margier ${ }^{\mathrm{c}, \mathrm{d}, \mathrm{e}}$, Emmanuelle Reboul $^{\mathrm{c}, \mathrm{d}, \mathrm{e}}$ \& Yoav D. Livney ${ }^{\mathrm{a}, \mathrm{b}}$

${ }^{a}$ Department of Biotechnology \& Food Engineering, Technion- Israel Institute of Technology, Haifa, 3200000 Israel.

${ }^{\mathrm{b}}$ Russell Berrie Nanotechnology Institute, Technion- Israel Institute of Technology, Haifa, Israel.

'INRA, UMR 1260 “Nutrition, Obesity and Risk of Thrombosis”, F-13385 Marseille, France

d INSERM, UMR 1062, F-13385 Marseille, France

${ }^{e}$ Aix-Marseille Université, F-13385 Marseille, France

The pandemic of vitamin D (VD) deficiency, and the global rise in obesity stimulate a need for staple low-fat foods and beverages enriched with VD. In light of consumer demand for a clean label, the use of natural endogenous food ingredients as delivery vehicles is of great interest. To this end, reassembled casein micelles $(\mathrm{rCM})$ have been shown to help retain VD during processing and shelf life as well as provide high bioavailability in low-fat milk and non-fat yoghurt. This follow up study focused on the performance of VD-loaded rCM after drying and reconstitution, considering VD retention during simulated digestion, and the subsequent in-vitro bioavailability of the vitamin. $\mathrm{RCM}$ conferred great protection to $\mathrm{VD}_{3}$ during simulated digestion with significant $(p<0.05)$ increase in vitamin retention for $1 \mathrm{~h}$ under gastric conditions. This observation is belived to arise from the vitamin-casein binding and the system's natural gelation (curd formation) near the casein isoelectric point that seclude the vitamin from environmental stressors and couple its release with digestive proteolysis of the rCM matrix. Vitamin absorption by Caco-2 cells from digested rCM was not significantly different from absorption of digested free VD. However, thanks to the highly protective effect of the rCM, against VD gastric degradation, the overall effect of the rCM was a 4-fold higher bioavailability, compared to the free VD. 


\section{Introduction}

Increasing evidence support the linkage between diet and human health ${ }^{1}$. This has led to numerous attempts to develop functional foods that carry added nutritional value. Such attempts include the enrichment and fortification of food with bioactive ingredients such as vitamins, polyphenols, essential fatty acids and carotenoids ${ }^{2}$. However, the incorporation of bioactive ingredients in food and drink systems poses several challenges. First, the enrichment of aqueous food or drink systems harbours a challenge of dosing accuracy and uniformity to avoid overdose, mainly in the case of oil-soluble bioactives, due to their poor solubility. Moreover, the incorporation of a bioactive ingredient within the food or drink system may result in its degradation and loss of activity during processing, product shelf life and digestion. Bioactive ingredients may cause unwanted effects on the sensory attributes of the enriched food system, and they can also react with other components present in the enriched system, which may decrease (or increase) their bioavailability ${ }^{1-3}$. To overcome these challenges, various bioactive delivery systems are being developed ${ }^{2}$. Delivery systems are commonly classified according to the main building blocks, which are necessarily GRAS (generally recognized as safe) food materials, preferably natural, and ideally- endogenous components of the product, thereby shortening the ingredient list and minimizing changes to the product sensory attributes, for higher consumer satisfaction. There are four main groups of delivery systems in food: protein-based, carbohydrate-based, lipid-based, and mixed systems $^{2}$. Due to the negative health implications of high fat consumption ${ }^{4,5}$, there is a need for enriching low-fat and non-fat food and drinks with health-promoting oil-soluble bioactives, preferably using non lipid, amphiphilic delivery systems.

Proteins are natural and diverse class of macronutrients, with various origins and techno-functionalities. Therefore, several studies have examined the development and use of protein-based delivery systems for lipophilic nutraceuticals ${ }^{6-13}$. Pertinent to vitamin $D(V D)$, soybean $\beta$-conglycinin ${ }^{10}$, corn protein hydrolysate $^{11}$, hydrophobins ${ }^{9}$, potato-protein ${ }^{14}$ and milk proteins ${ }^{8,12}$ have all shown good performances for the delivery of VD. Out of these, milk proteins seem particularly effective tools to deliver vitamins, 
minerals and lipophilic compounds, due to their evolutionary role in milk, which provides total nutrition to new-borns ${ }^{15}$.

The recommended dietary allowance (RDA) of VD is 600 international units (IU)/day for children over 12 months of age, adolescents and adults according to Institute of medicine report ${ }^{16}$. The RDA for elderly people above 70 years is $800 \mathrm{IU} / \mathrm{day}^{16}$. Nowadays, the actual daily consumption of VD is low and does not exceed 400 international units (IU), in most populations ${ }^{17,}{ }^{18}$. Modern lifestyle and minimization of exposure to sun light render natural production of VD in the skin (by UVB radiation) to be generally insufficient, even in sunny countries ${ }^{19}$. VD is not only biologically important but also associated with prevention of various diseases ${ }^{20,21}$, therefore, its supplementation to foods is a sensible public health measure.

This study focuses on the potential use of caseins, and particularly of re-assembled casein micelles (rCM), as delivery vehicles for VD and extend a few recent studies. First, $\mathrm{rCM}$ were shown to be suitable for the enrichment of reduced-fat products with VD and other oil-soluble nutraceuticals ${ }^{8,22,23}$. RCM were found to protect $\mathrm{VD}_{3}$ during UV exposure ${ }^{22}$, thermal treatment $\left(80^{\circ} \mathrm{C}, 1 \mathrm{~min}\right)$ and during 28 days of cold storage $^{8}$. Then, a clinical human study concluded that the bioavailability of VD encapsulated in rCM within $1 \%$ fat milk was at least as good as that of VD in a commercial dietary supplement aqueous formulation in which $\mathrm{VD}_{3}$ was emulsified using Tween $-80^{8}$. In another clinical trial, the enrichment of fatfree yoghurt with $\mathrm{VD}_{3}$ entrapped in $\mathrm{rCM}$ showed similarly high bioavailability as when using the synthetic surfactant Tween-80 ${ }^{24}$, though significantly better sensory properties were obtained with rCM. Another recent clinical study found that the bioavailability of VD in $\mathrm{rCM}$ in non-fat yoghurt was not significantly different from its bioavailability within the fat (in a $3 \%$ fat yoghurt), or in its presence (VD in rCM, in $3 \%$ fat yoghurt $)^{25}$.

The objectives of this follow up study were to evaluate the performance of the VD-loaded rCM after drying and reconstitution, and to gain deeper understanding of their behaviour during simulated digestion and of the consequent in-vitro bioavailability of the VD encapsulated in rCM. 


\section{Materials and Methods}

\subsection{Materials}

Commercial sodium caseinate (Casinella-QN 94.2\% protein Molkerei Meggle Wasserburg GMBH \& Co. KG) was kindly donated by Kelta Ltd. Israel and Molkerei Meggle Wasserburg GMBH \& Co. KG, Germany. $\mathrm{VD}_{3}$ in powder (USP grade), potassium phosphate dibasic (USP), potassium citrate tribasic monohydrate (FCC) and calcium chloride dihydrate (FCC), pepsin (Sigma P7000, $\geq 250$ units/mg protein), Trypsin (Sigma T0303, 13,000-20,0000 BAEE units/mg protein), chymotrypsin (Sigma C4129, $\geq 40$ units/mg protein), pancreatic lipase (Sigma L3126, 100-500 units/mg protein), sodium glycodeoxycholate (Sigma G9910) and taurocholic acid salt hydrate (Sigma T4009) were purchased from Sigma-Aldrich (Rehovot, Israel). Sodium chloride and Sodium bicarbonate were purchased from Frutarom Industries Ltd. (Herzliya, Israel) and Hydrochloric acid was purchased from Gadot group (Netanya, Israel). Dulbecco's modified Eagle's medium (DMEM) containing $4.5 \mathrm{~g} / \mathrm{L}$ glucose, penicillin/streptomycin, trypsin-EDTA $(500 \mathrm{mg} / \mathrm{L}$ and 200 mg/L, respectively) and PBS were purchased from Life Technologies (Saint Aubin, France). Fetal bovine serum was obtained from PAA (Vélizy Villacourblay, France).

\subsection{Methods}

2.2.1. $\mathrm{VD}_{3}$-casein binding characterization, $\mathrm{VD}_{3}$-loaded $\mathrm{rCM}$ preparation, $\mathrm{rCM}$ freeze-drying and reconstitution

Casein solution and $\mathrm{VD}_{3}$ loading: A solution of $6.11 \mathrm{mg} / \mathrm{ml}$ sodium caseinate was prepared with double distilled water and stirred overnight at room temperature for complete hydration prior to vitamin loading. Samples were prepared by adding ethanolic $\mathrm{VD}_{3}$ solution $(8 \mathrm{mg} / \mathrm{ml})$ into a vial containing either double distilled water or casein solution while vortexing, followed by gently stirring overnight at $4^{\circ} \mathrm{C}$. Final $\mathrm{VD}_{3}$ and caseinate concentrations in the samples were $260 \mu \mathrm{M}$ each. A control of casein solution at 
the same concentration without $\mathrm{VD}_{3}$ was prepared by the same procedure except that an equivalent amount of pure ethanol was added to the pre-dissolved sodium caseinate. Final ethanol concentration in the samples was $1.2 \%$.

Light microscopy: Light microscopy images of the pure $\mathrm{VD}_{3}$ dispersions in water (containing $1.2 \%$ ethanol) were compared to those of $\mathrm{VD}_{3}$ : casein 1:1 molar ratio solutions. Images were taken at $\times 40$ magnification using Olympus BX51 light microscope, operated in bright-field optical mode.

Binding studies by UV absorbance spectra measurements: The binding studies were performed according to the methods described by Israeli-Lev et al. ${ }^{9}$. UV-vis spectra were measured by UV spectrophotometer (Ultrospec 3000, GE Healthcare). All samples were diluted 10-fold before measurements. Measurements were made in duplicate at $23^{\circ} \mathrm{C}$.

Preparation of $\mathrm{VD}_{3}$ loaded $\mathrm{rCM}: \mathrm{VD}_{3}$ loaded $\mathrm{rCM}$ were prepared according to the protocol described by Haham et al. ${ }^{8}$ Briefly, to the solution of sodium caseinate loaded with $\mathrm{VD}_{3}$, described above, $\mathrm{K}_{2} \mathrm{HPO}_{4}$ and tri potassium citrate solutions were added, followed by drop wise addition of $\mathrm{CaCl}_{2}$ while stirring. Then, the samples were homogenized using a Micro-DeBee (Bee Int'I Inc., South Easton, MA, USA) ultra-high pressure homogenizer.

Freeze drying and reconstitution: $5 \%$ [wt/wt] Maltodextrin (MD, DE-18) was added to the $\mathrm{rCM}$ dispersion, as a cryoprotectant/drying aid, followed by stirring for $30 \mathrm{~min}$ at room temperature. Suspensions were then quench-frozen in liquid nitrogen and freeze-dried. Reconstitution was achieved by adding distilled water and stirring overnight at $4^{\circ} \mathrm{C}$. Particle size distribution of the rCM before and after freeze-drying and reconstitution were determined by dynamic-light-scattering (DLS) using NICOMP ${ }^{\mathrm{TM}}$ 380, Particle size/zeta potential analyser (PSS, Santa Barbara, CA, USA). Measurements were made at $23^{\circ} \mathrm{C}$. Particle size distributions were analysed by the NICOMP ${ }^{\mathrm{TM}}$ volume-weighted distribution analysis. $V D_{3}$ concentration before and after freeze-drying and reconstitution was evaluated by reversed phase (RP) HPLC. 


\subsubsection{Evaluation of $\mathrm{VD}_{3}$ bioaccessibility using an in vitro simulated digestion model}

Simulated digestion process: To assess casein digestibility and $\mathrm{VD}_{3}$ retention a semi-dynamic in vitro digestion model was applied and comprised of two steps: first a $1 \mathrm{~h}$ semi-dynamic gastric digestion followed by a two hour intestinal digestion step. In vitro digestion was based on a combination of the method described by C. Shani-Levi et al. ${ }^{26}$ and D. Dupont at al. ${ }^{27}$ with several modifications, with the most appreciable change done in the gastric $\mathrm{pH}$ profile adjusted to meet that of $\mathrm{P}$. Marteau et al. ${ }^{28}$ who worked on digestion of yoghurt. Simulated gastric fluid (SGF) was freshly prepared by dissolving $2 \mathrm{gr} \mathrm{NaCl}$ in $1000 \mathrm{ml}$ of double distilled water. Using $2 \mathrm{M} \mathrm{HCl}$, the $\mathrm{pH}$ was adjusted to 1.2 for pepsin dissolution, or to 5.0 for the initiation of the in vitro digestion model. In practice, the fresh $\mathrm{VD}_{3}$-loaded $\mathrm{rCM}$ were mixed with SGF (mixing ratio of $\mathrm{VD}_{3}$-loaded $\mathrm{rCM}: \mathrm{SGF} 1: 1 \mathrm{v} / \mathrm{v}$ ) and were transferred to $100 \mathrm{ml}$ water jacketed reactor (6.1418.250, Metrohm, Switzerland), maintained at $37^{\circ} \mathrm{C}$ with continuous blending ( $250 \mathrm{rpm}$ ) to mimic the stomach conditions. The initial $\mathrm{pH}$ was adjusted to 5 , and gastric pepsin $(170 \mathrm{U} / \mathrm{mg}$ casein, predissolved in SGF $\mathrm{pH}=1.2$ ) was added to mimic the initial conditions in the stomach. The $\mathrm{pH}$ was gradually titrated to 1.8 during 1 hour by a dual auto titration unit (Titrando 902, Metrohm, Switzerland) using $0.5 \mathrm{M} \mathrm{HCl}$. The simulated gastric step consisted of five stages; $\mathrm{pH}$ was maintained as 5 for $7.5 \mathrm{~min}$, then at $\mathrm{pH} 4.1$, for additional $7.5 \mathrm{~min}$, followed by $7.5 \mathrm{~min}$ at $\mathrm{pH} 3,7.5 \mathrm{~min}$ at $\mathrm{pH} 2.1$, and a final gastric step of 30 $\min$ at $\mathrm{pH}$ 1.8. The gradual titration was achieved using an auto-titration unit controlled by a dedicated software (Tiamo 2.3 software, Metrohm GA, Switzerland). Samples were then taken after 10, 30 and 60 min. Each sample was quench-frozen using liquid nitrogen to stop the enzyme activity. After 1 hour of simulated gastric step, the digesta underwent 2 hours of an upper intestinal step. Simulated duodenal fluid (SDF) solution was freshly prepared by dissolving $7.0 \mathrm{gr} \mathrm{NaCl}$ in $800 \mathrm{ml}$ distilled water and the $\mathrm{pH}$ was adjusted to 6.5 using $1 \mathrm{M} \mathrm{NaOH}$. Trypsin (34.5 U/mg casein), chymotrypsin (0.4 U/mg casein), pancreatic lipase $(58 \mathrm{U} / \mathrm{ml})$, sodium glycodeoxycholate $(4 \mathrm{mM})$ and taurocholic acid salt hydrate $(4 \mathrm{mM})$ were predissolved in SDF and were added to the digesta to mimic the intestinal conditions. The digesta $\mathrm{pH}$ was increased to 6.25 by titration with $1 \mathrm{M}$ sodium bicarbonate solution and maintained constant for 2 hours. 
Samples were then taken after 3, 10, 30 and $60 \mathrm{~min}$. Each sample was quench-frozen using liquid nitrogen to stop enzymatic activity.

Protein degradation and $\mathrm{VD}_{3}$ retention during simulated gastrointestinal digestion: The degradation of casein as a function of simulated digestion time was studied using sodium dodecyl sulfate-polyacrylamide gel electrophoresis (SDS-PAGE). The bands of the protein were stained by coomassie brilliant blue. $\mathrm{VD}_{3}$ retention as function of digestion time was assessed following the protocol of Kazmi et al. ${ }^{29}$. Briefly, $0.5 \mathrm{ml}$ of each sample was transferred into a test tube. A $1.6 \mathrm{ml}$ of mixture of methanol and chloroform $(2: 1 \mathrm{v} / \mathrm{v})$ was added to each test tube, followed by mixing for 20 seconds. $1 \mathrm{ml}$ of chloroform was then added to each tube, and mixed for $1 \mathrm{~min}$. Samples were then centrifuged for $10 \mathrm{~min}$ at $1,500 \mathrm{~g}$ at $4^{\circ} \mathrm{C}$. From each test tube, $1.2 \mathrm{ml}$ of the clear chloroform bottom layer was transferred to an evaporation vial using a glass syringe. The extract was dried from chloroform under a flow of nitrogen gas, reconstituted in $0.75 \mathrm{ml}$ of the reversed phase HPLC (RP-HPLC) mobile phase [methanol: acetonitrile: water (49.5:49.5:1 v:v:v)], and equilibrated for 15 min. $V D_{3}$ was quantified by RP-HPLC using HP 1100 system with $4.6 \times 250 \mathrm{~mm}$ Vydac 201TP C18 column, a diode array detector and an auto-sampler. Twenty microliter samples were run under isocratic flow of $1.3 \mathrm{ml} / \mathrm{min}$. The area under the curve at $267 \mathrm{~nm}$ (maximal VD absorbance wavelength) was calculated for $\mathrm{VD}_{3}$ quantification. The ratio between the area under the curve at $228 \mathrm{~nm}$ and $254 \mathrm{~nm}$ was calculated for $\mathrm{VD}_{3}$ identification.

\subsection{3. $\mathrm{VD}_{3}$ in-vitro bioavailability analysis: uptake by Caco-2 cells}

VD ${ }_{3}$ uptake experiments: Caco-2 clone TC7 cells were cultured as previously described ${ }^{30,31}$. Cells were seeded and grown in trans-wells for 21 days to obtain confluent and highly differentiated cell monolayers ${ }^{30,31}$. Twelve hours prior to each experiment, the media in apical and basolateral chambers were replaced by serum-free complete medium. At the beginning of the experiment, cell monolayers were washed with $0.5 \mathrm{~mL}$ PBS. The apical side of the cell monolayers received either the digested $\mathrm{VD}_{3^{-}}$ loaded $\mathrm{rCM}$ or the digested free $\mathrm{VD}_{3}$ diluted in $\operatorname{DMEM}(1 / 8)$, and the basolateral side received serum-free complete medium. After 1 hour of cell exposure with the samples, cells were washed with $0.5 \mathrm{~mL}$ ice-cold 
PBS, then scraped and collected in $0.5 \mathrm{~mL}$ PBS. Absorbed $\mathrm{VD}_{3}$ was estimated as $\mathrm{VD}_{3}$ present in harvested cells or transported to the basolateral side. All the samples were sealed under nitrogen and stored at $80^{\circ} \mathrm{C}$ until analysed.

$V D_{3}$ extraction: $V D_{3}$ was extracted from $500 \mu \mathrm{L}$ aqueous samples using the following method. Distilled water was added to sample volumes below $500 \mu \mathrm{L}$ to reach a final volume of $500 \mu \mathrm{L}$. Ergocalciferol $\left(\mathrm{VD}_{2}\right)$, routinely used as internal standard, was added to the samples in $500 \mu \mathrm{L}$ ethanol. The mixture was extracted once with two volumes of hexane. The hexane phase obtained after centrifugation $(500 \mathrm{~g}$, $10 \mathrm{~min}, 4^{\circ} \mathrm{C}$ ) was evaporated to dryness under nitrogen, and the dried residue was dissolved in $200 \mu \mathrm{L}$ of mobile phase ( $60 \%$ acetonitrile $-38 \%$ methanol - $2 \%$ water). A volume of $180 \mu \mathrm{L}$ was used for HPLC analysis.

VD $_{3}$ analysis by HPLC: The HPLC system comprised a Shimazu separation module (LC-2OADSP HPLC Pumps and SIL-20CHT autosampler, Shimazu, Champs-sur-Marne, France), an SPD-M20A Shimadzu photodiode array detector (PDA, detection at $265 \mathrm{~nm}$, spectral analysis between 190 and $300 \mathrm{~nm}$ ). VD 3 and $\mathrm{VD}_{2}$ were separated using a $250 \times 4.6 \mathrm{~nm} \mathrm{RP} \mathrm{C} \mathrm{C}_{18}, 5 \mu \mathrm{m}$ Zorbax column (Interchim, Montluçon, France)

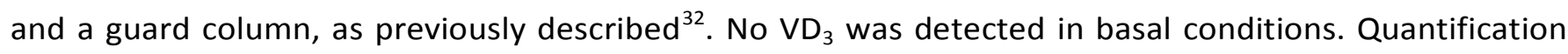
was performed using Chromeleon software (version 6.50 SP4 Build 1000, Dionex) comparing peak area with standard reference curves. All solvents used were HPLC grade from SDS (Peypin, France).

\section{Results and discussion}

Extending previous studies on $\mathrm{rCM}^{8,24,25,33}$, this study sought better understanding of the technofunctionality and digestive fate of this delivery system and particularly its implications to VD retention and bioavailability.

\subsection{Light microscopy}


Light microscopy images of pure $\mathrm{VD}_{3}$ in water and $V \mathrm{D}_{3}$ of the same concentration in the presence of casein (1:1 molar ratio), are presented in Figure 1. $\mathrm{VD}_{3}$ concentration in the examined samples was 0.1 $\mathrm{mg} / \mathrm{ml}(260 \mu \mathrm{M})$. The casein: $\mathrm{VD}_{3}$ molar ratio was chosen to be similar to the molar ratio we use in $\mathrm{rCM}$. At this concentration and after an overnight storage at $4^{\circ} \mathrm{C}$, it can be seen from Figure $1 \mathrm{a}$ that $\mathrm{VD}_{3}$ forms micron-sized aggregates. However, in the presence of casein, a clear solution is obtained without any visible particles under the light microscope (Figure $\mathbf{1 b}$ ), indicating submicron co-assembly of the $\mathrm{VD}_{3}$ and the casein. From this comparison, we can qualitatively conclude that caseins bind $\mathrm{VD}_{3}$.

\subsection{Binding studies by UV absorbance spectra measurements}

The UV-absorbance spectrum of casein-only, $V D_{3}$-only, and casein- $\mathrm{VD}_{3}$ solutions were measured to qualitatively examine whether binding had occurred. The difference between the mathematical summation of UV-absorbance spectrum of the $\mathrm{VD}_{3}$-only solution and that of the casein-only solution, and the UV-absorbance spectrum of their solution together is an indication for binding ${ }^{9}$. Observing Figure 2, it can be seen that the mathematical summation curve is lower than that of the mixed casein- $\mathrm{VD}_{3}$ solution, indicating association between casein and $\mathrm{VD}_{3}$. The results indicate that casein and $\mathrm{VD}_{3}$ associate at this molar ratio (1:1), an assumption supported by the light microscopy images (Figure 1).

\subsection{Freeze drying and reconstitution}

Freeze-drying is widely used for improving chemical and physical stability and extending shelf-life of colloidal systems ${ }^{34}$. During the freezing step there is phase separation into ice and freeze-concentrated solution. The high nanoparticle concentration in this phase may induce irreversible aggregation ${ }^{34}$. Moreover, adsorption to ice may lead to protein denaturation ${ }^{35}$. To minimize the harmful effect of the freeze-drying process, cryoprotectants are often added. Saccharides are the most popular cryoprotectants in food, as they protect proteins from denaturation, and promote matrix immobilization by raising the glass transition temperature, thereby preventing nanoparticle aggregation ${ }^{34,36}$. After their freeze-drying in the presence of $\mathrm{MD}, \mathrm{rCM}$ were reconstituted by addition of water and stirring overnight. We have observed their reconstitution visually and by size distribution measurements by DLS, and the results are presented in Figure 3. The volume-weighted size distributions shows that rCM samples before 
and after freeze-drying and reconstitution exhibited bimodal distributions (Figure 3). The first subpopulation was comprised of nanoparticles smaller than $100 \mathrm{~nm}$ and the second was in the range of 100-350 $\mathrm{nm}$. The volume-weighted-size distribution of the $\mathrm{rCM}$ before freeze-drying was in line with the previous work performed by our group ${ }^{8}$. It can be seen in Figure 3 that freeze-drying and reconstitution slightly increased the volume weighted percentage of the larger subpopulation, while that of the smaller one decreased accordingly, but shifted to lower sizes. That resulted in a minor visual difference between the samples; it can be seen in the inset of Figure $\mathbf{3}$ that the reconstituted sample (2) is slightly more turbid than the fresh sample (1). However, the process did not significantly affect the average size and it was even slightly lower after reconstitution (average size of $95 \pm 2 \mathrm{~nm}$ and $89 \pm 0.3 \mathrm{~nm}$ before and after freeze-drying and reconstitution respectively). About $90 \%$ of the VD was retained during the freezedrying and reconstitution process (concentration of $167 \pm 8 \mu \mathrm{g} / \mathrm{ml}$ and $151 \pm 0.3 \mu \mathrm{g} / \mathrm{ml}$ before and after freeze-drying and reconstitution, respectively). These results indicate that freeze-drying aided by MD, and reconstitution, had only a minor influence on the rCM size distribution, the visual appearance and the concentration of VD.

\subsection{Simulated gastric and intestinal digestion}

In vitro digestion models are often used to screen and interrogate food delivery systems ${ }^{37}$. Various simulated digestion models exist, mimicking the complex physicochemical and physiological conditions in the human gastrointestinal tract ${ }^{37}$. Varying environmental conditions such as $\mathrm{pH}$, ionic strength and enzyme activity induce structural and chemical changes in the delivery system which may trigger bioactive release ${ }^{37}$ but might also cause its degradation. To assess casein digestibility and the retention of $V D_{3}$ remaining in the lumen of the human gastrointestinal tract, samples of $V_{3}$ loaded $r C M$ and free VD were challenged by a semi-dynamic human digestion model. Results of direct observations, assessment of digestive proteolysis and determination of VD retention are presented in Figures 4-6. As can be seen in Figure 4, under gastric conditions, $\mathrm{VD}_{3}$ loaded $\mathrm{rCM}$ formed large curd clots, due to the proximity to the isoelectric point of casein $\left(\mathrm{pH}=4.6^{15}\right)$ and the activity of pepsin ${ }^{38}$. The aggregate size significantly decreased in one hour of simulated gastric digestion, as can be seen in Figure 4. Pepsin 
activity along with the gradual $\mathrm{pH}$ decrease below the isoelectric point, expectedly increased the solubility of the casein as well as its susceptibility to proteolysis. The observed casein clot degradation during the gastric phase was in-line with our SDS-PAGE results shown in Figure 5.

In lane 1 it is possible to see the initial protein composition in the $\mathrm{VD}_{3}$ loaded $\mathrm{rCM}$ suspension. The four casein fractions, $\alpha_{\mathrm{s} 1^{-}}, \alpha_{\mathrm{s2} 2^{-}}, \beta$ - and $\mathrm{K}$ - caseins were observed in molecular weight range of 19-25 KDa as naturally present in bovine milk ${ }^{15}$. The other bands in lane 1 , whose sizes were lower than $19 \mathrm{KDa}$, were probably residual whey proteins such as $\beta$-lactoglobulin and $\alpha$-lactalbumin (18.3 KDa and $14.2 \mathrm{KDa}$ respectively ${ }^{15}$ ) from the sodium caseinate. A few weaker higher-MW bands above 40kDa are also seen, which may be serum albumin, lactoferrin and immunoglobulins, or some casein aggregates which weren't completely dissociated during sample preparation (less likely).

Lanes 2-4 represent the $\mathrm{VD}_{3}$ loaded $\mathrm{rCM}$ under simulated gastric conditions after 10, 30 and 60 min respectively. In these lanes it is possible to witness the degradation of the caseins, as the bands representing the four casein fractions diminished and smaller peptides (2-15 KDa) appeared. The bands whose sizes were between 25 and $37 \mathrm{KDa}$, were apparently pepsin, but possibly also degradation products of the higher MW bands seen in lane 1. By the end of the simulated gastric phase, the large clot was enzymatically digested and only casein peptides remained (Figure 4 and Figure 5- lane 4). Our results regarding the gastric breakdown of the caseins are in accord with the literature ${ }^{15,38,39}$. After 60 min of simulated gastric digestion, the digesta $\mathrm{pH}$ was raised to 6.25 , and trypsin, chymotrypsin, lipase and bile salts were added to mimic duodenal conditions. Lanes 6-10 (Figure 5) represent 10, 30, 60, 90 and 120 min of simulated upper intestinal digestion. In these lanes it is possible to see bands in the size range of approximately 20-25 KDa which represent the intestinal chymotrypsin, trypsin and lipase that were added in this stage. The addition of duodenal enzymes expectedly caused further casein digestion. Several bands of casein peptides were observed in lane 6 representing a sample taken after 10 min of simulated duodenal digestion. These bands were not observed in samples taken after 30 min or more of simulated duodenal conditions (lanes 7-10). These SDS-PAGE results are in-line with the visual observations, as the digesta became more transparent with proceeding simulated digestion (Figure 4). In 
the absence of protein no significant changes were observed over 60 min of simulated gastric digestion, as the vitamin remained dispersed in water and the system remained turbid (Figure 4). During the duodenal phase the system was clarified, most likely due to the addition of bile salts, natural surfactants known to solubilize lipid-soluble compounds and breakdown products, and to form mixed micelles ${ }^{40}$. To study $\mathrm{VD}_{3}$ retention during simulated gastric and duodenal digestion, extraction of $\mathrm{VD}_{3}$ from the aqueous phase was performed, followed by its quantitative determination by RP-HPLC analysis. Results are presented in Figure 6. It can be seen from Figure 6 that the presence of protein improved $\mathrm{VD}_{3}$ stability during simulated gastric and intestinal digestion (retention of $\sim 85 \%$ vs. $\sim 15 \%$ at the end of simulated digestion process in presence and absence of protein respectively). $V D_{3}$ is sensitive to the presence of acid conditions and high temperatures, however, $\mathrm{VD}_{3}$ has better stability under neutral and alkaline conditions $^{41}$. As mentioned above, the initial $\mathrm{pH}$ of the simulated gastric phase was 5 , which was gradually decreased to 1.8 during one hour. Expectedly, in the absence of protein only $37 \%$ of the vitamin survived under these acidic conditions. At the beginning of the simulated duodenal phase the $\mathrm{pH}$ was increased to 6.25 and maintained constant for two hours. Under these conditions $\mathrm{VD}_{3}$ was less susceptible to degradation, and only additional $13 \%$ of the free vitamin were degraded in this phase, resulting in $15 \%$ of the initial $\mathrm{VD}_{3}$ remaining after both simulated digestion stages. During simulated digestion of $\mathrm{VD}_{3}$ loaded $\mathrm{rCM}$, after $10 \mathrm{~min}$ of the gastric phase, there was an apparent decrease of the $\mathrm{VD}_{3}$ residual amount to $40 \%$, however, the apparent residual amount was then increased to $73 \%$ and $90 \%$ after 30 and 60 min of the gastric phase, respectively. Moreover, the measurement results of these samples were characterized by large error bars. As discussed above, at the beginning of the simulated gastric phase large casein aggregates formed, as seen in Figure 4. It is likely that most of the vitamin was entrapped in these aggregates, thus the samples taken from the bulk during the gastric phase contained less $V D_{3}$ and do not accurately represent the overall $V D_{3}$ retention status at this stage. The residual amount at the beginning of the duodenal phase, after breakdown and dissolution of the large aggregates, was $90 \%$ and it remained relatively constant during this phase. It can be seen in Figure 4 that during the duodenal phase, the casein aggregates were digested and the digesta was clarified, making the sample 
more homogenous. Thus, it is plausible that the $\mathrm{VD}_{3}$ was no longer entrapped in casein aggregates but was extracted into mixed micelles and was more uniformly dispersed in the digesta. Therefore, the samples taken at this point better represent the actual $\mathrm{VD}_{3}$ retention status. Hence, the high values of remaining $\mathrm{VD}_{3}$ during the duodenal phase, demonstrate the protection conferred to the vitamin by the $\mathrm{rCM}$ mainly under simulated gastric digestion conditions. The use of protein nanovehicles to protect $\mathrm{VD}_{3}$ during simulated digestion was previously examined. Levinson et al. ${ }^{10}$ found that $92 \%$ of the initial $\mathrm{VD}_{3}$ concentration survived a two hours simulated gastric step digestion as the $\mathrm{VD}_{3}$ was complexed within soybean $\beta$-conglycinin nanoparticles (relative to $50 \%$ retention for $\mathrm{VD}_{3}$ in phosphate buffer $\mathrm{pH} 6.8$ ). Lin et al. ${ }^{11}$ found that nanocomplexes of corn protein hydrolysate $(\mathrm{CPH})$ with $\mathrm{VD}_{3}$ with $\mathrm{CPH}: \mathrm{VD}_{3}$ mass ratio of 15:1 and higher conferred protection to the vitamin during simulated digestion (1 hour simulated gastric step followed by 2 hours upper intestinal step), as the remaining vitamin concentration was approximately $95 \%$ of its initial concentration ${ }^{11}$. Markman et al. also observed protection of VD by casein and casein-MD Maillard conjugates at $\mathrm{pH} 2.5^{42}$.

\section{5 $\mathrm{VD}_{3}$ in-vitro bioavailability analysis by Caco-2 cells}

$\mathrm{VD}_{3}$ in vitro bioavailability within $\mathrm{rCM}$ has been examined using Caco- 2 cells. The results are presented in Figure 7. Caco-2 cells were exposed to $\mathrm{VD}_{3}$-loaded $\mathrm{rCM}$ and to free $\mathrm{VD}_{3}$ samples taken after simulated digestion including one hour of a gastric step and two hours of upper-intestinal step. Cell exposure time with the digested samples was one hour. This exposure duration was chosen in view of the approximate exposure time of the digesta with a given intestinal epithelial cell, expected to occur in the small intestine considering atypical transit rate ${ }^{43}$, and stomach content/chyme volume ${ }^{44}$ (e.g. assuming a typical chyme volume of $1000 \mathrm{ml}$ and intestinal flow rate of $15 \mathrm{ml} / \mathrm{min}$, exposure time is $\sim 66 \mathrm{~min}$ ). The uptake of $\mathrm{VD}_{3}$ in both formulations is presented in Figure 7A. The $V D_{3}$ uptake rates were low for both formulations (approximately $10 \%$ and $15 \%$ uptake of $V D$ for digested $V D_{3}$-loaded $r C M$ and for digested free $\mathrm{VD}_{3}$, respectively). The absorption rate for the digested free $\mathrm{VD}_{3}$ was slightly, though not significantly higher, compared to that of digested $\mathrm{VD}_{3}$-loaded $\mathrm{rCM}$. Taken together with the much higher retention, due to the protective effect of the $\mathrm{rCM}$ and the curd-aggregates they form mainly under the acidic gastric 
conditions, the overall effect of the rCM was that a four-fold higher proportion of the ingested vitamin was bioavailable in vitro, compared to the unencapsulated VD (Figure 7B). These results regarding the high overall effect of $\mathrm{rCM}$ are in-line with the high oral bioavailability of VD observed in our preceding clinical studies. It is likely that VD was protected against the harmful acidic environment in vivo by its entrapment within the large protein clots formed at the beginning of the gastric step of digestion (as observed herein), and this can partly explain the high in vivo oral bioavailability obtained.

\section{Conclusions}

We studied the performance of VD-loaded $\mathrm{rCM}$ after drying and reconstitution, considering VD retention during simulated digestion, and the subsequent in-vitro bioavailability of the vitamin. Our results provided qualitative evidences for binding of $\mathrm{VD}_{3}$ and caseins, using light microscopy and UV absorbance spectra measurements. Such $\mathrm{VD}_{3}-\mathrm{rCM}$ co-assemblies aided by MD were well reconstituted after freezedrying. The freeze-drying and reconstitution had marginal influence on the size distribution of the $\mathrm{VD}_{3^{-}}$ loaded $\mathrm{rCM}$, on their visual appearance and on the $\mathrm{VD}_{3}$ concentration. Encapsulated $\mathrm{VD}_{3}$ was also found to be significantly protected during simulated gastric and upper-intestinal conditions, compared with $\mathrm{VD}_{3}$ dispersed in water. The $\mathrm{VD}_{3}$ in-vitro bioavailability examined using Caco-2 cells indicated low uptake rates for both formulations, apparently due to limitations of this colon cell-based model (as our clinical studies $^{8,25,45}$ showed high bioavailability). However, taken together with the much higher retention of the encapsulated $\mathrm{VD}_{3}$ during digestion, the overall observed effect of $\mathrm{rCM}$ was an improved oral bioavailability of $\mathrm{VD}_{3}$ compared to the unencapsulated $\mathrm{VD}_{3}$. Thus, this work provides yet another support for the great potential of $\mathrm{rCM}$ to ensure efficient and more sustainable delivery of sensitive hydrophobic bioactive compounds in food.

\section{Acknowledgements}


The authors would like to thank Mrs. Maya Bar-Zeev and Dr. Carmit Shani-Levi for their technical assistance.

\section{References}

1. Y. D. Livney, Curr. Opin. Food Sci., 2015, 3, 125-135.

2. R. C. Benshitrit, C. S. Levi, S. L. Tal, E. Shimoni and U. Lesmes, Food \& Function, 2012, 3, 10-21.

3. P. M. M. Schrooyen, R. v. d. Meer and C. G. D. Kruif, Proceedings of the Nutrition Society, 2001, 60, 475479.

4. T. R. Frieden and D. M. Berwick New England Journal of Medicine, 2011, 365, e27.

5. C. L. Ogden, M. D. Carroll, C. D. Fryar and K. M. Flegal, NCHS data brief, 2015, 219, 1-8.

6. S. David, Y. Zagury and Y. D. Livney, Food Biophysics, 2015, 10, 195-206.

7. F. Diarrassouba, G. Garrait, G. Remondetto, P. Alvarez, E. Beyssac and M. Subirade, Food Chemistry, 2015, 173, 1066-1072.

8. M. Haham, S. Ish-Shalom, M. Nodelman, I. Duek, E. Segal, M. Kustanovich and Y. D. Livney, Food \& Function, 2012, 3, 737-744.

9. G. Israeli-Lev and Y. D. Livney, Food Hydrocol, 2014, 35, 28-35.

10. Y. Levinson, G. Israeli-Lev and Y. D. Livney, Food Biophysics, 2014, 9, 332-340.

11. Y. Lin, Y.-H. Wang, X.-Q. Yang, J. Guo and J.-M. Wang, LWT - Food Science and Technology, 2016, 72, 510517. 
12. N. Ron, P. Zimet, J. Bargarum and Y. D. Livney, International Dairy Journal, 2010, 20, 686-693.

13. F.-P. Chen, N. Zhang and C.-H. Tang, LWT - Food Science and Technology, 2016, 72, 125-133.

14. S. David and Y. D. Livney, Food Hydrocol, 2016, 57, 229-235.

15. Y. D. Livney, Current Opinion in Colloid \& Interface Science, 2010, 15, 73-83.

16. A. C. Ross, J. E. Manson, S. A. Abrams, J. F. Aloia, P. M. Brannon, S. K. Clinton, R. A. Durazo-Arvizu, J. C. Gallagher, R. L. Gallo, G. Jones, C. S. Kovacs, S. T. Mayne, C. J. Rosen and S. A. Shapses, The Journal of Clinical Endocrinology and Metabolism, 2011, 96, 53-58.

17. M. S. Calvo, S. J. Whiting and C. N. Barton, The Journal of Nutrition, 2005, 135, 310-316.

18. M. Kiely and L. J. Black, Scandinavian journal of clinical and laboratory investigation. Supplementum, $2012,243,14-23$.

19. A. Steinvil, E. Leshem-Rubinow, S. Berliner, D. Justo, T. Finn, M. Ish-shalom, E. Y. Birati, V. Shalev, B. Sheinberg and O. Rogowski, Eur J Clin Invest, 2011, 41, 263-268.

20. E. Reboul, Food \& Function, 2015, 6, 356-362.

21. S. Pilz, M. Grubler, M. Gaksch, V. Schwetz, C. Trummer, B. Ó. Hartaigh, N. Verheyen, A. Tomaschitz and W. Marz, Anticancer Research, 2016, 36, 1379-1387.

22. E. Semo, E. Kesselman, D. Danino and Y. D. Livney, Food Hydrocol, 2007, 21, 936-942.

23. P. Zimet, D. Rosenberg and Y. D. Livney, Food Hydrocol, 2011, 25, 1270-1276.

24. Y. Levinson, S. Ish-Shalom, E. Segal and Y. D. Livney, Food \& Function, 2016, 7, 1477-1482.

25. Y. Cohen, S. Ish-Shalom, E. Segal, O. Nudelman, A. Shpigelman and Y. D. Livney, Journal of Functional Foods, 2017, 30, 321-325.

26. C. Shani-Levi, S. Levi-Tal and U. Lesmes, Food Hydrocolloids, 2013, 32, 349-357.

27. D. Dupont, G. Mandalari, D. Molle, J. Jardin, J. Léonil, R. M. Faulks, M. S. J. Wickham, E. N. Clare Mills and A. R. Mackie, Molecular Nutrition \& Food Research, 2010, 54, 767-780.

28. P. Marteau, M. Minekus, R. Havenaar and J. H. J. Huis In't Veld, Journal of Dairy Science, 1997, 80, 10311037.

29. M. Tippetts, S. Martini, C. Brothersen and D. J. McMahon, Journal of Dairy Science, 95, 4768-4774. 
30. P. Borel, G. Lietz, A. Goncalves, F. Szabo de Edelenyi, S. Lecompte, P. Curtis, L. Goumidi, M. J. Caslake, E. A. Miles, C. Packard, P. C. Calder, J. C. Mathers, A. M. Minihane, F. Tourniaire, E. Kesse-Guyot, P. Galan, S. Hercberg, C. Breidenassel, M. González Gross, M. Moussa, A. Meirhaeghe and E. Reboul, The Journal of Nutrition, 2013, 143, 448-456.

31. A. Goncalves, B. Gleize, S. Roi, M. Nowicki, A. Dhaussy, A. Huertas, M.-J. Amiot and E. Reboul, The Journal of Nutritional Biochemistry, 2013, 24, 1751-1757.

32. E. Reboul, A. Goncalves, C. Comera, R. Bott, M. Nowicki, J. F. Landrier, D. Jourdheuil-Rahmani, C. Dufour, X. Collet and P. Borel, Mol Nutr Food Res, 2011, 55, 691-702.

33. E. Semo, E. Kesselman, D. Danino and Y. D. Livney, Food Hydrocolloids, 2007, 21, 936-942.

34. W. Abdelwahed, G. Degobert, S. Stainmesse and H. Fessi, Adv Drug Deliv Rev, 2006, 58, 1688-1713.

35. E. Cao, Y. Chen, Z. Cui and P. R. Foster, Biotechnol. Bioeng., 2003, 82, 684-690.

36. R. Edelman, I. Kusner, R. Kisiliak, S. Srebnik and Y. D. Livney, Food Hydrocol, 2015, 48, $27-37$.

37. S. J. Hur, B. O. Lim, E. A. Decker and D. J. McClements, Food Chemistry, 2011, 125, 1-12.

38. A. Ye, J. Cui, D. Dalgleish and H. Singh, Food Hydrocolloids, 2016, 52, 478-486.

39. P. L. H. McSweeney and P. F. Fox, Advanced dairy chemistry. basic aspects Volume $1 A$, Volume $1 A$, Springer, New York; London, 2013.

40. B. E. Goodman, Advances in Physiology Education, 2010, 34, 44-53.

41. G. F. Combs Jr, The vitamins, Academic press, 2012.

42. G. Markman and Y. D. Livney, Food \& Function, 2012, 3, 262-270.

43. K. D. Fine, C. A. Santa Ana, J. L. Porter and J. S. Fordtran, Gastroenterology, 108, 983-989.

44. J. N. Hunt and W. R. Spurrell, The Journal of Physiology, 1951, 113, 157-168.

45. Y. Levinson, S. Ish-Shalom, E. Segal and Y. D. Livney, Food Funct, 2016, 7, 1477-1482. 


\section{Figure captions:}

Figure 1: $V D_{3}$ and casein form submicron co-assemblies. Light microscope images of (a) pure VD in water (containing $1.2 \%$ ethanol), (b) VD: casein $1: 1$ molar ratio in water (containing $1.2 \%$ ethanol). VD concentration was equal in both samples $(0.1 \mathrm{mg} / \mathrm{ml})$. Scale bar: $50 \mu \mathrm{m}$.

Figure 2: UV absorbance spectra measurements indicating casein-VD $\mathrm{D}_{3}$ binding. The UV-Vis absorbance spectra of pure $\mathrm{VD}_{3}$ in water (black, dashed), of casein solution in water (grey, dashed), of mixed $\mathrm{VD}_{3}$ and casein (black, solid) and of the mathematical summation of the absorbance spectra of $\mathrm{VD}_{3}$ alone and casein alone (grey, solid). [VD $3=26 \mu \mathrm{M}$, [casein] $=26 \mu \mathrm{M}$.

Figure 3: Freeze-drying aided by maltodextrin has only a minor influence on the size distribution and visual appearance of $\mathrm{rCM}$ suspensions. Volume-weighted size distributions of $\mathrm{VD}_{3}$ loaded casein micelles before (solid line) and after (dashed line) freeze-drying and reconstitution with distilled water, determined by DLS; Inset: Vials containing: $\mathrm{VD}_{3}$ loaded casein micelles before (1) and after freeze-drying and reconstitution with distilled water (2).

Figure 4: Visual observations of in vitro digestion of free VD3 in water and VD3 loaded rCM show differences in colloidal stability, and its changes during digestion. 
Figure 5: RCM are digested mainly during the gastric step of the digestion process. SDS-PAGE breakdown analysis of $\mathrm{VD}_{3}$-loaded $\mathrm{rCM}$ under two-step simulated digestion process consisting a one hour gastric step and a two hour upper-intestinal step, as a function of time. Lanes: (1) $r C M-V D_{3}$ suspension mixed with simulated gastric fluids (SGF), without pepsin (suspension: SGF ratio= 1:1 v/v) (2) gastric digestion- $10 \mathrm{~min}$. (3) gastric digestion- $30 \mathrm{~min}$ (4) gastric digestion- $60 \mathrm{~min}$, (5) size markers (top to bottom): 250, 150, 100, 75, 50, 37, 25, 20, 15, 10, 5, $2 \mathrm{kDa}(6) 10 \mathrm{~min}$ duodenal digestion, (7) $30 \mathrm{~min}$ duodenal digestion, (8) 60 min duodenal digestion, (9) 90 min duodenal digestion, (10) 120 min duodenal digestion.

Figure 6: The entrapment in $\mathrm{rCM}$ improved $\mathrm{VD}_{3}$ stability during simulated gastric and intestinal digestion. Retention of $V D_{3}$ during simulated gastric and intestinal digestion of free $\mathrm{VD}_{3}$ (dashed) and $V D_{3}$ loaded rCM (solid) as a function of time. Notice that the apparent drop in VD during the gastric step was due to its entrapment in curd clots which were not very accessible upon sampling, and the real remaining concentration was revealed only upon complete curd breakdown in the intestinal stage.

Figure 7: The overall effect of the $\mathrm{rCM}$ is a higher proportion of the ingested vitamin being bioavailable in vitro, compared to the unencapsulated VD. Percentage of $\mathrm{VD}_{3}$ absorbed (taken-up and transported) by Caco- 2 cells after simulated gastric and intestinal digestion of $\mathrm{VD}_{3}$-loaded $\mathrm{rCM}$ and of free $\mathrm{VD}_{3}$; $(\mathrm{A}) \mathrm{VD}$ uptake as percent of the amount found in the digesta after one hour of simulated gastric digestion and two hours of simulated upper-intestinal digestion; (B) VD absorbed as percent of initial VD amount at the beginning of simulated digestion; Different letters indicate significantly different results within each chart. 

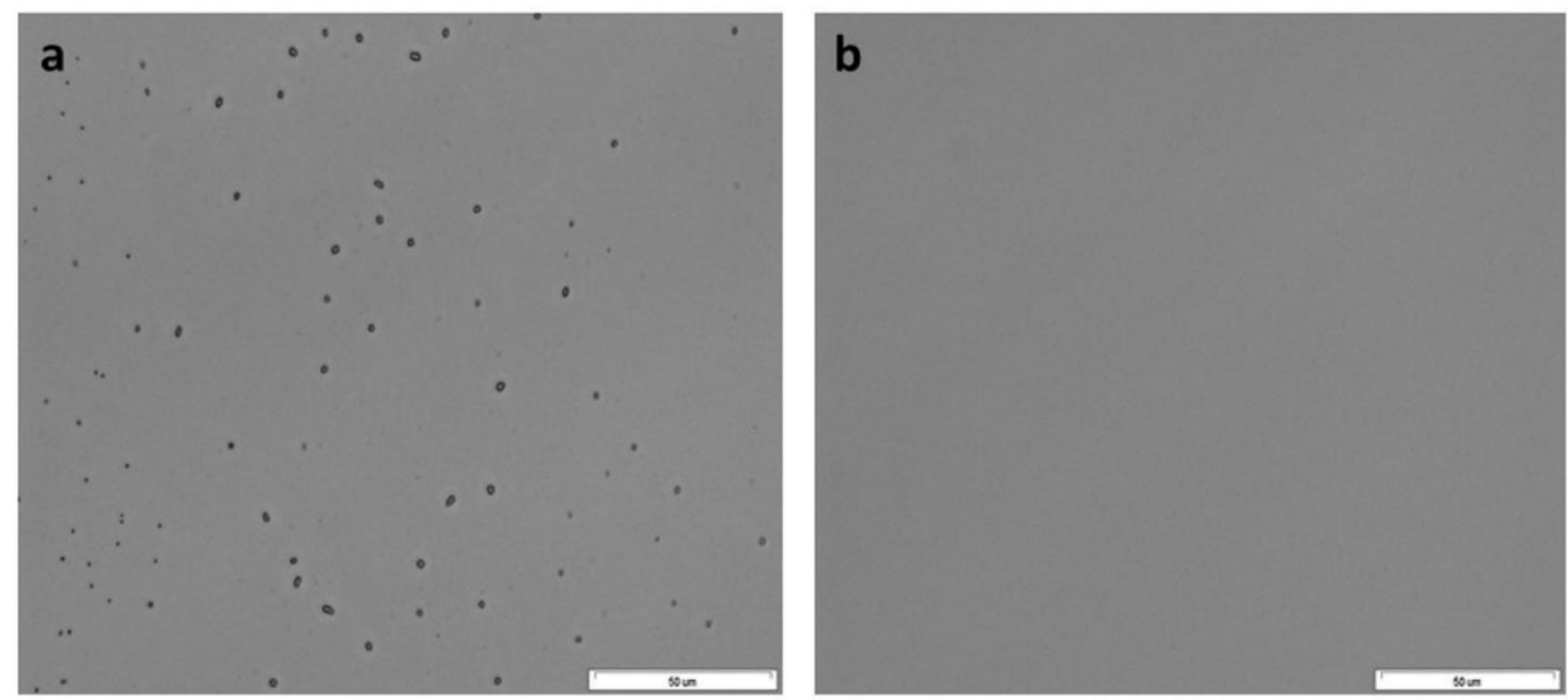

Figure 1: 
Figure 2:

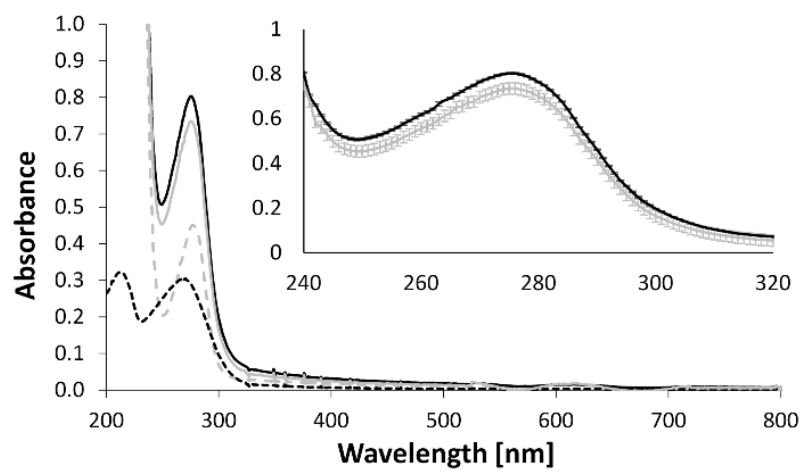




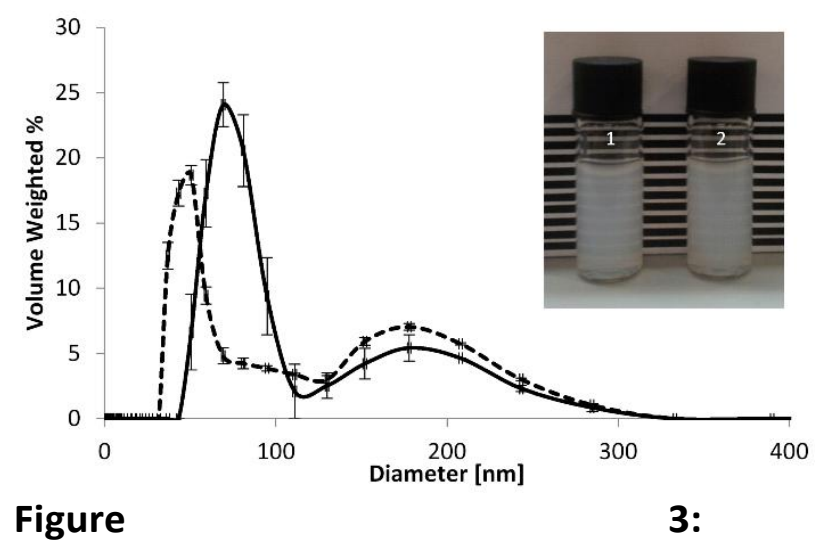




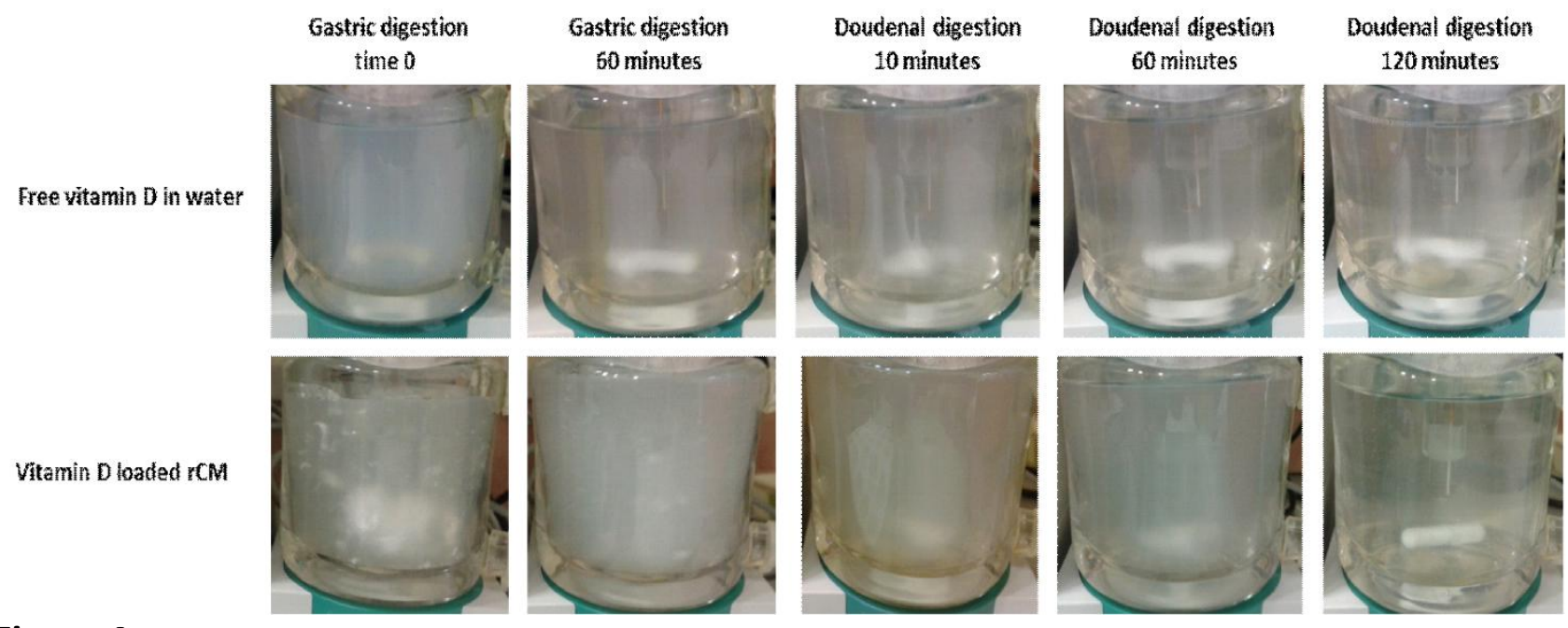

Figure 4: 


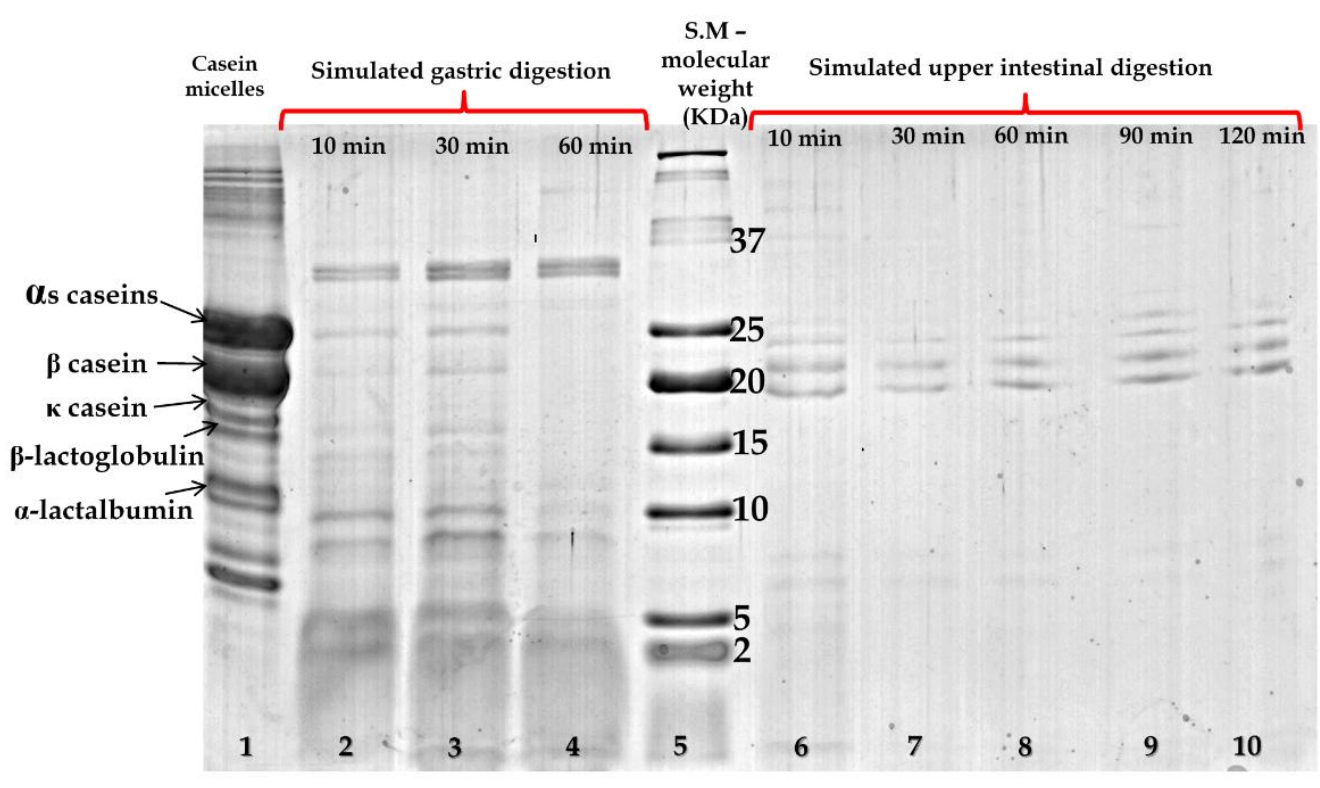




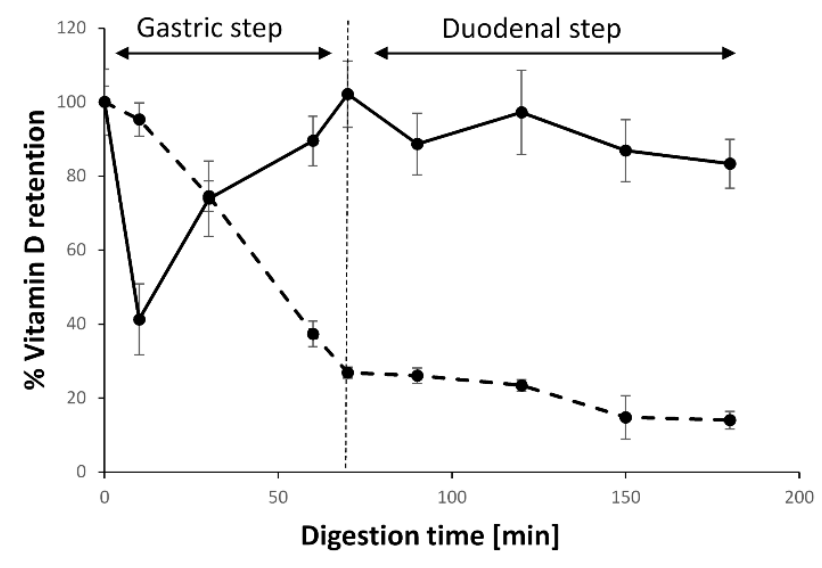

Figure 6: 

Figure 7:
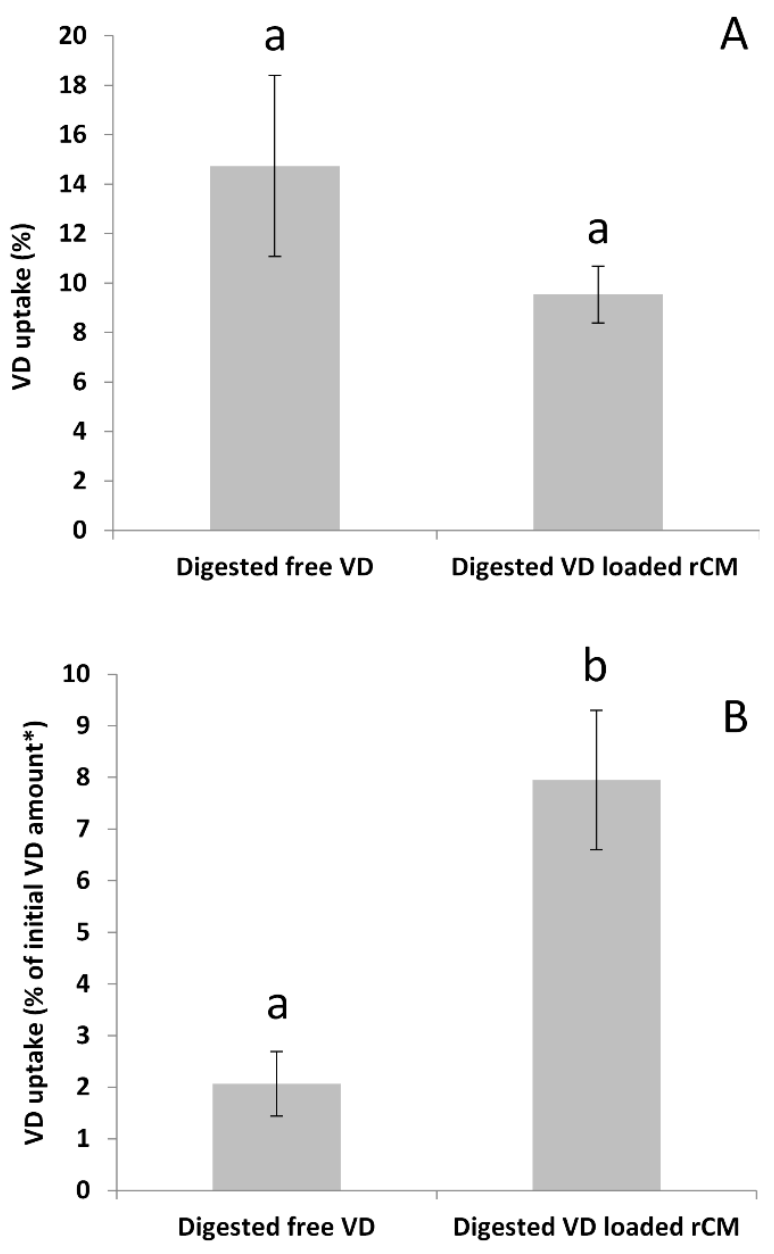